\title{
Knowledge Comparison Between Pediatrics And Emergency Medicine Residents About Pediatrics Cardiopulmonary Resuscitation
}

\author{
Nader Tavakoli', Shahyad Tajoddini' ${ }^{2}$ Samad Shams Vahdati ${ }^{3}$, \\ Nastaran Kazemi ${ }^{4}$, Mostafa Vafaei Aghdam 5 \\ 1 Emergency Department, Tehran University of Medical Science \\ ${ }^{2}$ Emergency Department, Kerman University of Medical Science \\ ${ }^{3}$ Emergency Department, Tabriz University of Medical Science \\ ${ }^{4}$ Tabriz University of Medical Science \\ ${ }^{5}$ Tehran University of Medical Science
}

\begin{abstract}
Introduction: The aim of this study is to compare the level of knowledge about Pediatrics Cardio Pulmonary Resuscitation (CPR) between pediatrics and emergency residents.

Method: In this cross-sectional study, the standard questionnaire about pediatrics Advanced Life Support (ALS) is filled by pediatrics and emergency residents, residents choose by convenience method and data from check list and questionnaires noted in SPSS and the ALS questionnaire score is compared between two groups.

Results: In this study 39 pediatrics and 41 emergency medicine residents were evaluated. Confidence about CPR knowledge was higher in Emergency medicine residents. The average Score was 19.24
\end{abstract}

$(S D=3.36)$. But there is no significant statistical difference between two groups in ALS score. There were no relation between ALS score and confidence. Third-year Pediatrics residents had significantly lower score than others.

Conclusion: According to the results of this study, pediatrics and emergency medicine residents have low knowledge about pediatric ALS and there is a need for holding special workshops for them.

Keywords: Pediatric Advanced Life Support; pediatric residents; emergency medicine residents

Aplication: 19.03.2012 Accepted: 07.08.2012

\section{Introduction}

Cardio Pulmonary Resuscitation (CPR) is a process in which resuscitation of vital organs ( heart, lung and brain) are done to prolong life for patients. In the past CPR was performed by putting a tube (which is connected to a breathing machine) through the mouth, pressing on the chest and painful physical stimulations. But over time and progress in science, major developments have been established in these measures. Nowadays, recovery operations are performed in two steps; Basic support (BS) and Advanced cardiac Life Support (ALS); by use of 
medications and advanced equipments. ${ }^{1}$

Success rate of CPR depends on various factors including: age, underlying diseases, time interval between cardiopulmonary arrest and initiation of CPR and preparedness of participants in resuscitation team.

The main problem in preserving lives of patients by performing CPR is the lack of adequate knowledge and skills of the physicians, bystanders, nurses and even physicians responsible for primary care about necessary and appropriate measures. Consequently these groups especially the ones who are professionally involved in care and treatment should learn resuscitation issues and pre-hospital and hospital activities and increase their skills during training courses. Physicians who benefit from pre-hospital resuscitation skills have wider ability in performing therapeutic measures and patients health preservation. ${ }^{2}$ Regarding the fact that a part of the patients referred to emergency departments are children, emergency specialist and residents should be as familiar as or even more than pediatric specialists and residents and act better.

So the aim of this study is to review of pediatric and emergency residents' knowledge about advanced pediatric CPR and compare between two groups.

\section{Method and material}

This is a cross-sectional study conducted by questionnaire.

Study design: All the Rasul-e-akram hospital's pediatric and emergency residents of first, second and third year were included in the study. The questionnaire attached to the proposal is filled by emergency medicine and pediatric resident. Answer sheets' headers are separated and the persons responsible for correcting the answer sheets don't know the owner of them and their belonging groups.

Tools: The prepared check list is coincided by the variants in the study and the questionnaire is prepared according to American Heart Association.
Analysis: The collected information in the check list is entered in the statistical software, SPSS 15.0, and analyzed. Central indexes like average and median and distribution index, standard deviation, are calculated. Chi-square and t-test statistical tests are used for data analysis.

Ethics: Residents' all information is kept confidential by researchers and the results would be announced without mentioning residents' names.

\section{Results}

80 residents were in the study that 39 of them $(48.75 \%)$ were pediatric residents and 41 (51.25\%) were emergency medicine residents.

$33(41.25 \%)$ of studied residents were first-year residents, 28 (35\%) were second-year and 19 (23.75\%) were third-year residents.

16 of pediatric residents were first-year residents, 13 were second-year residents and 10 were third-year residents. While 17 of the emergency medicine residents were first-year residents, 15 were second-year and 9 were third-year residents.

The average obtained score was $19.24(\mathrm{SD}=3.36)$ and residents' score was ranging from 9 to 24 . (Chart 1)

In comparison between the average score gained from pediatric ALS, pediatric residents' average score was 18.52(SD=3.84) and emergency medicine residents' average score was $19.61(S D=3.07)$ and there was no significant statistical difference between two groups. $(p=0.232)$

First-year residents' average ALS score was 18.96 $(S D=2.59)$, second year residents' average score was $19.83(S D=2.98)$ and third-year residents' average score was 18.79 (SD=4.96) and there was no significant statistical difference among groups. 
Chart 1: ALS score histogram

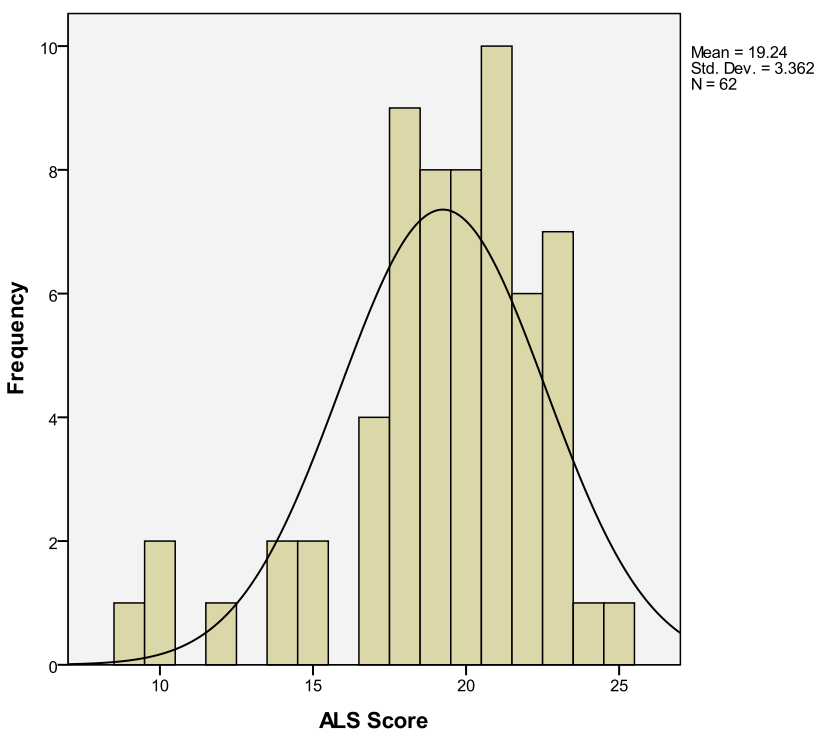

ALS average score among pediatric residents was as following:

First-year residents' average score was 19.13, secondyear residents' was 20.50 and third-year residents' was 14.40 .

\section{ALS average score among emergency medicine resi- dents was as following:}

First-year residents' average score was 18.88, secondyear residents' was 19.47 and third-year residents' was 21.22

There was no significant statistical difference between first-year residents of pediatric and emergency medicine. $(p=0.832)$

There was also no difference between obtained ALS questionnaire scores of second year residents in two groups.

Pediatric third-year residents' average score was 14.40 $(S D=5.32)$ and emergency medicine third-year residents' average score was $21.22(S D=2.68)$, which indicates a significant statistical difference between two groups. $(p=0.007)$

\section{Discussion}

The main problem in preserving the lives of the patients by performing CPR is the lack of adequate knowledge and skills of the patients, bystanders, nurses and even physicians responsible for primary care about necessary and appropriate measures. Consequently these groups, especially the ones who are professionally involved in care and treatment, should learn resuscitation issues and pre-hospital and hospital activities and increase their skills during training courses. Physicians who benefit from pre-hospital resuscitation skills have wider ability in performing therapeutic measures and patients' health preservation. $^{3}$

The point is whether or not we can accomplish good performance in medicine graduates. Several studies conducted about CPR education show the importance of this field. Some of these studies focused on the need for educating medical students about principles and methods of maintaining patient's life. ${ }^{4,5}$

Especially these studies indicate that despite the importance of this field, yet there is a little attention in the curriculum of medical universities to teach preserving patients' life by interesting and appropriate methods.

So our need is not just quantitative increase of CPR education, our more important aim is to increase the quality of training.

There are numerous problems related to traditional methods of CPR such as: No match between educational program and the needs of participants, teachers' efficacy in training, lack of allocated appropriate time for practice, lack of proper supervision on training, Disregarding to students ideas.

New approach to clinical training techniques has begun since recent decades which goes based on practical training. 
Studies shows that practical education and objective training which is done more accurate and in more time, lead to better educational results. ${ }^{6-8}$

For example, neonatal resuscitation training done by computer simulation method or workshop basis has led to increase knowledge level and learner's skill promotion. ${ }^{9,10}$ in order to increase CPR graduates' knowledge and ability modern methods in medical education should be chosen that not only lead to better and deeper learning but also cause more long-term learning effect.

By taking appropriate learning strategy we can be hopeful that in case of facing real cases, medical graduates can save patients' lives better.

Physicians who benefit from pre-hospital resuscitation skills have wider ability in performing therapeutic measures and patient's health preservation ${ }^{2}$. In a study by Laurent et al. in 2007 on 76 dentistry senior students, only $53 \%$ (40 students) expressed that they have enough knowledge and ability to do CPR ${ }^{11}$. In another study by Graham et al. in 1994 on graduated medical students, educational status and CPR training were evaluated by the questionnaires.

$87 \%$ of them were well trained but only $52 \%$ of them agreed the effectiveness of this training. ${ }^{12}$

In this study, 62 residents were studied that 21 (33.9\%) were pediatric residents and 41 (66.1\%) were emergency medicine residents.

In comparison between the scores obtained from pediatric ALS questionnaires, the average score of pediatric residents $(S D=3.84)$ was 18.52 and the average score of emergency medicine residents $(S D=3.07)$ was 19.61 that there was no significant statistical difference seen between two groups. $(p=0.232)$

This issue can demonstrate that all the pediatric and emergency medicine residents would better participate in training workshops for getting more information in this field.

Third-year pediatric residents scored significantly lower that other pediatric residents and third-year emergency medicine residents. It seems that there has been more negligence regarding the training of these residents.

\section{Conclusion}

According to the results of this study, the information of pediatric and emergency medicine residents surveyed in this study about pediatric ALS is low and the lack of participation in pediatric ALS training workshops shows the necessity to hold purposive and modern workshops to raise their level of knowledge. And the Participation in these workshops should be mandatory for promotion of first year residents to higher years.

\section{References}

1. Jiresaty RM., Liss JP., Basu SK., Follow up of 122 patients who survived cardiac arrest.Resuscition, 1973, 2: 191

2. Jafarian A., Assessment success rate of cardio pulmonary resuscitation in Shohadaie Hafte Tir Hospital. Journal of Iran University of medical science. Fall 2008,9(30):327

3. Cummins RO, Ornato JP, Thies WH, Pepe PE. Improving survival from sudden cardiac arrest: the chain of survival concept: a statement for health professionals from the Advanced Cardiac Life Support Subcommittee and the Emergency Cardiac Care Committee, American Heart Association. Circulation 1991 May; 83(5):

1832-47.

4. Travers DA, Mears G. Physicians' experiences with prehospital do-not-resuscitate orders in North Carolina. Prehosp Disaster Med 1996 Apr-Jun; 11(2): 91-100

5. Schimmel EM. The hazards of hospitalization. Ann Intern Med 1964 Jan; 60: 100-10.

6. Steel K, Gertman PM, Crescenzi C, Anderson J. latrogenic illness on a general medical service at a university hospital 1981. Qual Saf Health Care 2004 Feb; 13(1): 76-80.

7. Brennan TA, Leape LL, Laird NM, Hebert L, Localio AR, Lawthers 
AG, et al. Incidence of adverse events and negligence in hospitalized patients: results of the Harvard Medical Practice Study I 1991. Qual Saf Health Care 2004 Apr; 13(2): 145-52.

8. Ahmed HU, Kellett C, Ashworth M, Nazir S. First aid and cardiopulmonary resuscitation training for medical students. Med Educ 2004 Aug; 38(8): 913.

9. Robak O, Kulnig J, Sterz F, Uray T, Haugk M, Kliegel A, et al. CPR in medical schools: learning by teaching BLS to sudden cardiac death survivors: a promising strategy for medical students? BMC Med Educ 2006 Apr 28; 6: 27.
10. McConnell EA. Clearing the way for a CPR. Nurs Manage 2000 Jul; 31(7): 49-50.

11. Florian Laurent, Pascal Augustin, Cathy Nabet, Sophie Ackers ,et al.Managing a Cardiac Arrest: Evaluation of Final-Year Predoctoral Dental Students. Journal of Dental Education.2009

12. C.A. Graham, K.A. Guest \& D. Scollon .Cardiopulmonary resuscitation. Paper 1: a survey of undergraduate training in UK medical schools. Journal of Accident and Emergency Medicine 1994. 11, 162-165 